Journal of Engineering and Applied Sciences 14 (10): 3158-3174, 2019

ISSN: 1816-949X

(C) Medwell Journals, 2019

\title{
High Temperature Effect on Shear Transfer Strength of Steel Fiber Reinforced Self-Compacted Concrete
}

\author{
Ola Adel Qasim and Abdullah Sinan Ahmed \\ Department of Civil Engineering, AL-Mansour University College, Baghdad, Iraq
}

\begin{abstract}
Effect of micro steel fiber under exposition to the raised temperatures was studied on shear transformation strength of Self-Compacting Concrete (SCC) experimentally, analytically and numerically by the push-off test. Four groups of 27 testing specimens were performed. Three groups were heated to room temperature, $100,200,400,600$ and $800^{\circ} \mathrm{C}$. The main adopted variables were fiber percentage with the volume fraction of $0,1.0$ and $2.0 \%$ and area of reinforcement which perpendicular to shear plane $\left(\rho_{\mathrm{vfy}}\right)$. The experimental results show that steel fiber increases shear strength and higher shear reinforcement retained higher strength values after exposure to temperatures. A newly introduced comparison equation was concluded based on the theoretical and analytical study of experimental data and available data from other researchers based on different variables, compressive strength, fibers factor, area of reinforcement. Proposed equation and finite element results show good agreement for the direct shear strength with experimental results.
\end{abstract}

Key words: Self-compacted concrete, steel fiber, push-off test, temperature, shear strength and finite element, push-off test

\section{INTRODUCTION}

It is known that the type of failure of concrete elements exposed to shear forces is a brittle failure (ACI., 2008). Previous studies have shown the importance of using steel fiber in concrete (Miao et al., 2003). The use of the fiber improves the concrete properties of tensile strength, compressive strength, elasticity, ductility, toughness and shear strength in concrete sections of any structural member. The addition of the fiber increases the ability of concrete to resist the forces that are exposed to it which leads to the emergence of fractures and cracks where fiber has the ability to prevent the emergence or reduction of cracks propagations and this represents the most important step to face the problems in concrete (Almusawee, 2012). The current development of the concrete technology and facilities leads to more special requirements that must be provided in the concrete. The concrete must have high tensile, compressive strength and durability. At the same time, the concrete must be economical and produce strong and economical concrete. As a result of the work requirements and evolution technologies, all of this led to the appearance of Self-Ccompacted Concrete (SCC), the concrete of a special type that does not need compactness for its use which leads to speed of work and does not require shakers as it flows in molds at high speed as a result of it weigh only without the influence of external factors and without segregation (Gencel et al., 2011; Ferrara et al., 2007). But the only problem with this type of concrete is the low tensile strength, low cracking resistance and the limited ductility that is required to obtain high resistance and fast workability. The appearance of the fiber and the use of ordinary concrete led to the idea of the use of fiber in this type of concrete as the fiber has the ability to increase the absorption of energy after cracking and improved the ductility in concrete. The addition of the fiber to the concrete leads to a decrease in workability, so, plasticizers need to be applied to make the concrete meet all the requirements of the concrete workability. Transfer of shearing forces in the reinforced concrete structural element is significant in many types of reinforced concrete structures including ordinary and deep beams, corbels, brackets, shear walls, shear diaphragms and construction joints. The shear transfer problem was examined previously by many researchers. The push-off test specimen is more suitable for studying shear transfer in such structures than conventional beams which is most widely used to study the influence of direct shear stresses (Lee and Foster, 2006; Al-Feel, 2006; Cuenca and Serna, 2010; Boulekbache et al., 2012).

There are many forces that are subjected to concrete structures such as wind load, earthquakes, floods and fires which cause problems and weaknesses in buildings. One of the most important problems facing the structures and cause high damages is exposure to fires which cause

Corresponding Author: Ola Adel Qasim, Department of Civil Engineering, AL-Mansour University College, Baghdad, Iraq 
exposure to high temperatures at a specific time making the structures member subject to high strain in a short time (Ahmed, 2013). Not only the fire is the only way to expose to high temperatures but the use of concrete in special structure or industrial buildings which exposed to the high temperature like (industrial oven walls and chimneys, surfaces below boilers and nuclear reactor building). Previous studies of some researchers (Lee and Foster, 2006; Mohuder and Meshri, 2001) show that the exposure of concrete to different temperatures leads to deterioration and the effectiveness of concrete and its properties as a result of exposure to high strain additionally to loads used to design. As a result of the weakness, the residual strength and durability remained in concrete which depends on many factors (temperature degree, exposure time, cooling methods, heat extinguishing, type and concrete used). After continuous research, the study noted the existence of a few practical or theoretical studies on the effect of the use of fiber on the properties and behavior of concrete after exposure to different types of temperature, all of which leads to the need to conduct research and additional practical studies to study the effect of high temperatures and its types on the characteristics of concrete with applying fiber types of different shapes and sizes.

Self-Compacting Concrete (SCC): SCC (Self-Compacted Concrete) is one of the most important developments in civil engineering and concrete technology. These types of concrete do not require the use of electric vibrators and its effect on disturbing the work in terms of sound, cost, energy and slow work where it can be used in higher places and height because it relies on its power flow and flow based on the weight to achieve high compression compacted pressure (ACI., 2008; Miao et al., 2003). This type of concrete is highly efficient in work and has proved to be effective in all parts of the construction members but the only problem facing concrete is its exposure to shear force. In order to overcome this type of problem, steel fibers which are randomly distributed in concrete have been used to ensure that they are not assembled and worked in a homogeneous manner to increase the bearing strength of the concrete, increase its tensile strength and increase its elasticity, stiffness and tensile strength (Almusawee, 2012). This type of concrete is required whenever construction shows a need to increase durability or safety measures from the required building design standards. The fiber has the ability to improve concrete performance by reducing cracks and conveying the stresses generated by loads through cracks (Gencel et al., 2011). Self-compacting concrete is an excellent type of concrete that meets all the requirements of structure and combines the strength with ease of work (workability) which can be combined with other types of concrete to make a good construction that having more than one common characteristic which can be combined with the fiber that dependent on the type, fiber shape, the aspect ratio, the fiber length, the volume of fibers and the content of the fibers (Ferrara et al., 2007).

Research significance: The shear force that passes through the concrete depends on several factors including the efficiency, strength, quality of concrete and contribution of reinforcing steel bar. Several studies have been carried out whether theoretical or practical on the method of shear transfer using many tests, shapes and different types of concrete. Khaloo and Kim (1997) presented an experimental study on the shear force transfer by the adopting (push off) method test for shear transfer and using the high strength self-compacted concrete for casting the specimens and mold. The study concluded that the shear force depends on many factors, like (the amount of aggregate used) which affect the appearance of fractures and the method of expansion of fractures where during the loading process it found that this type of concrete makes the fractures be widespread but with the small width. Cuenca and Serna (2010) studied the process of shear transfer by means of a test (push-off) but with the use of the fiber in the self-compacted concrete mixture, the fiber used including certain percentages like $\left(0,40\right.$ and $\left.60 \mathrm{~kg} / \mathrm{m}^{3}\right)$. Their study included a comparison between steel fiber self-compacted concrete specimens with specimens casting with ordinary concrete where they found that the effect of the fiber increases the strength and shear strength of the specimen's and also reduce the fractures. Boulekbache et al. (2011) in this study, they investigated the influence of the shear forces and their transfer through the concrete. Their research includes the study of the behavior of a prismatic model made of the different concrete strength of 30,60 and $80 \mathrm{MPa}$. The type of fiber used in this study was (hooked-end) used to enhance the concrete strength and study the effect of the fibers on them and in volume ratios of $0,0.5$ and $1 \%$ and the aspect ratio ranging from $(65-80)$. Their research concludes that the best and fastest way to increase the strength of concrete exposed to shear strength is by increasing the concrete compressive strength. The second summary of the research is that the use of additional materials such as steel fiber in concrete mix increases the hardness of the concrete and the compressive strength where they have demonstrated that the increase of steel fiber by $0.5-1.0 \%$ increases the shear strength by 44 and $65 \%$. The third evidence in the research shows that the increase of aspect ratio 
(from $65-80 \%$ ) found it does not affect enough but affects with a small percentage which does not exceed (5\%). The use of the finite element method identified by some of the theoretical programs used to represent the shear force was studied by some researchers. Mohuder and Meshri (2001) they used the method of the finite elements to represent the shear force transferred through the (push-off test) subjected to direct shear forces on a concrete model with or without compressive stress subjected laterally. Studies have demonstrated the susceptibility of this type of program to the representation of this type of tests and the method of transmission of shear forces through it.

There are many methods to find the shear force transmission. One of the methods is the (Push-off test) method with or without reinforcement bars. This research used (Push-off test) to find the shear strength transferred through the concrete using self-compacted concrete with the containment of certain percentages of the fiber. Where the effect of fiber was studied scientifically on the method of transmission of the shear and studies the limited and specified ratios and quantities that help to carry part of the shear loads with the presence of reinforcing steel or without. The exposure of concrete structures to high temperatures leads to deterioration of the building as in the exposure of buildings to fires, this temperature changes the behavior of the concrete used and consequently, damage of building and may be subject to collapse. The impact of high temperatures affects the behavior of concrete and its properties in terms of (compressive, bending, torsion, shear and tensile strength) due to deterioration of properties of materials made the concrete under the influence of high strains. There are many practical and theoretical studies published previously under the influence of high temperatures on the strength and behavior of materials made from various concrete types but there is little practical and theoretical research on the effect of high temperatures on the properties of concrete exposed to shear strength as the information's published in the researches are still limited and part of them do not meet all design requirements. Also in previous research, there are no approved design equations to study the effect of temperature on the concrete members exposed to shear forces.

An experimental study is presented, here, on the shear transfer strength of SFSCC performance subjected to direct shear by push-off test under the influence of very high raised temperatures up to $800^{\circ} \mathrm{C}$. Four groups fabricating and testing specimens were performed. Three groups were heated to $0,100,200,400,600$ and $800^{\circ} \mathrm{C}$ while an original specimen for a definite collection experimented without heating being a beginning specimen. The main variables to be studied were fiber percentage with volume fraction for steel fibers of $0,1.0$ and $2.0 \%$ values and the shear reinforcement ratio crossing the shear plane at right angles. Finite element model with different variables was adopted for shear transfer strength of concrete which showed good agreement with experimental results. Depend on the experimental study results, a new suggested equation obtained and determined based on experimental data in this investigation and possible data from researchers depends on different variables; compressive strength, fibers factor and area of reinforcement. The suggested formula has the great prediction of the shear strength applied directly to the tested specimens.

Properties of fresh concrete: The behavior of self-compacted concrete is defined, classified and determined on the basis of its conduct in the fresh state. One way to identify the behavior of concrete in case it meets certain specific requirements for its use or not is through the published principles mentioned in the specifications such as EFNARC the slump flow, $\mathrm{T}_{50}$ and the L-box test were used for all mixes of this study as illustrated in Table 1 which is depends on the consequences of the certain three tests and the limitations of EFNARC, ACI-237R07 listed. It is obvious from (Table 1 and Fig. 1-3) that the addition of fibers with 1 and

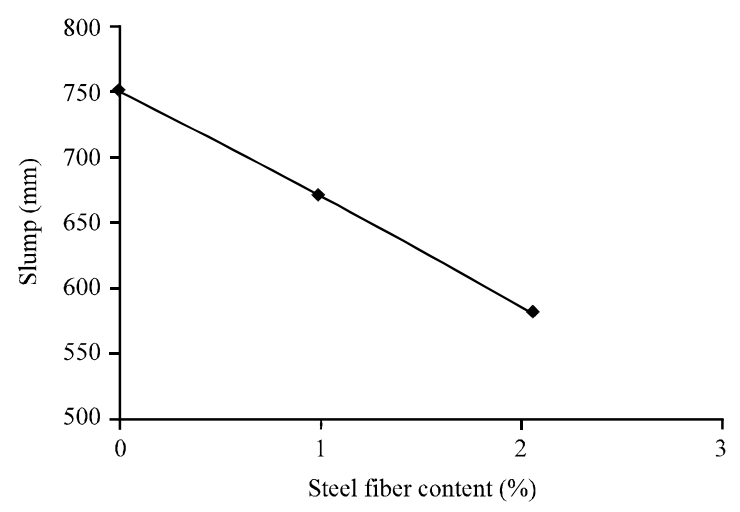

Fig. 1: Effect of steel fiber content on slump test (mm)

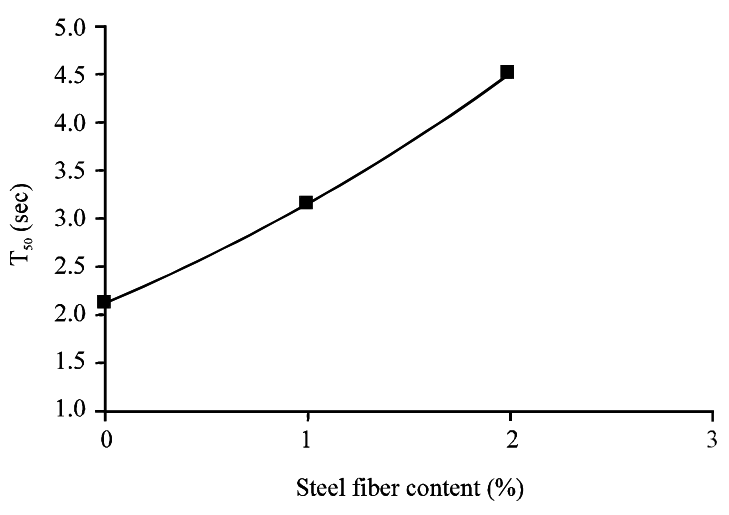

Fig. 2: Effect of steel fiber content on $\mathrm{T}_{50}(\mathrm{sec})$ 
Table 1: Mix design proportion of SCC and results of fresh concrete properties

\begin{tabular}{lllllllllll}
$\begin{array}{l}\text { Mix } \\
\text { design }\end{array}$ & $\begin{array}{l}\text { Cement } \\
\left(\mathrm{kg} / \mathrm{m}^{3}\right)\end{array}$ & $\begin{array}{l}\text { Sand } \\
\left(\mathrm{kg} / \mathrm{m}^{3}\right)\end{array}$ & $\begin{array}{l}\text { Aggregate } \\
\left(\mathrm{kg} / \mathrm{m}^{3}\right)\end{array}$ & $\begin{array}{l}\text { Silica fume } \\
\left(\mathrm{kg} / \mathrm{m}^{3}\right)\end{array}$ & $\begin{array}{l}\text { Superplasticizer } \\
\left(\mathrm{L} / \mathrm{m}^{3}\right)(\%)\end{array}$ & $\begin{array}{l}\text { Steel fiber } \\
\mathrm{W} / \mathrm{c}\end{array}$ & $\begin{array}{l}\text { Slump } \\
(\mathrm{mm})\end{array}$ & $\begin{array}{l}\mathrm{T}_{50} \\
(\mathrm{sec})\end{array}$ & $\begin{array}{l}\mathrm{L}-\text {-box } \\
\left(\mathrm{H}_{2} / \mathrm{H}_{1}\right)\end{array}$ \\
\hline Mix 1 & 430 & 840 & 675 & 130 & 4.5 & 0.49 & 0 & 750 & 2.1 & 0.97 \\
Mix 2 & 430 & 840 & 675 & 130 & 4.5 & 0.49 & 1 & 670 & 3.14 & 0.88 \\
Mix 3 & 430 & 840 & 675 & 130 & 4.5 & 0.49 & 2 & 580 & 4.5 & 0.8 \\
Limit of EFNARC & & & & & & & & $650-800$ & $2-5$ & $0.8-1$ \\
Limit of ACI-237 & & & & & & & & $450-760$ & $2-5$ & $0.8-1$ \\
\hline
\end{tabular}

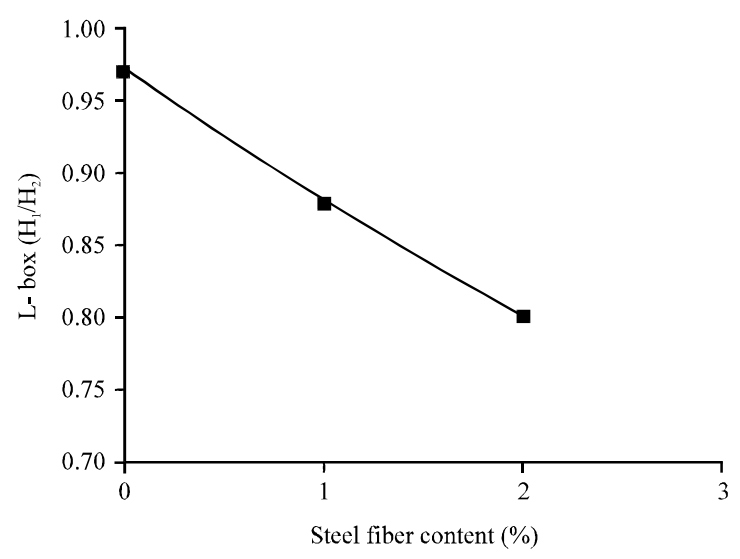

Fig. 3: Effect of steel fiber content on L-box

$2 \%$ decreases the slump flow by 10 and $22 \%$, increasing $\mathrm{T}_{50}(49$ and $114 \%$ ) reduction L-box by 9 and $17.5 \%$. This reduction of workability is due to the presence of steel fibers that work as the obstacle for the motion of mix components. The concrete can be characterized by the following properties which only can be classified and represent as an $\mathrm{SCC}$, if it meets all the requirements mentioned.

Filling ability (unconfined flowability), this is known under the label of the ability of the SCC concrete to flow unlimited to fill the mold with its full volume, depending only on the impact of its weight.

Passing ability (confined flowability) which can be defined based on the ability of the concrete to flow and passing through narrow spaces which is similar to the usual situation during the casting and the impact of reinforcing steel and its ratios through the mold and the space left behind which allows the passage of concrete without interruption.

Segregation resistance (stability) which can be defined on the basis of the time required to ensure that concrete remains uniform and homogenous during transport and casting.

Viscosity can be evaluated by $\mathrm{T}_{50}$ Time through the slump-flow examination or estimated by the $\mathrm{V}$-funnel flow time, the time amount collected does not estimate the viscosity of SCC, however, it is associated to it by specifying the rate of flow. Concrete with a moderate viscosity ought certainly quick initial flow and later stop. Concrete including a high viscosity may proceed to creep ahead across an elongated time.

\section{MATERIALS AND METHODS}

Cement: In this research, the only cement used for casting all the molds was Iraqi cement (type-1 ASTM) which meets all requirements of Iraqi and American specifications (No. 5/1984) and (ASTM C150-89).

Fine aggregate and coarse aggregate: One type of fine sand and coarse gravel $(<10 \mathrm{~mm})$ was used to mix all types of concrete and cast all the molds. It meets all the chemical and physical requirements of Iraqi and B.S. Specifications (No. 45/1984) and (B.S. No. 882/1992).

Mineral admixture Silica Fume powder (SF): For the production of self-compacted concrete with a high specification and high strength, additives were used in this research. One of the additives materials is silica fume which is a fine material similar to cement and may be added to the concrete mixture in addition or replacement. It a produce from productions of silicon or metal silicon. It is a very fine material compared to the size of cement particles as it is 100 times smaller. It meets the chemical and physical conditions of the concrete in accordance with (ASTM C1240-05).

Chemical admixture high range water reducing agent (superplasticizer): The superplasticizer employed was a transformed polycarboxylates based polymer fabricated and provided by SIKA company. It was employed in constructing all the specimens as a high limit water-reducing admixture as mentioned in (ASTM C494-05). It has three functions, i.e., superplasticizer, viscosity modifying agent and retarder. This is better than using the three admixtures individually which might be incompatible and cause complicity in the mixture. Superplasticizer material used in concrete mixes to increases its strength and ability in compressive, shear, bending and tensile strength which it's applying leads to this improvement and it came from the results of reducing the water. 


\begin{tabular}{|c|c|c|c|c|c|c|c|}
\hline $\begin{array}{l}\text { Size } \\
(\mathrm{mm})\end{array}$ & $\begin{array}{l}\text { Surface } \\
\text { texture }\end{array}$ & $\begin{array}{l}\text { Area } \\
\left(\mathrm{mm}^{2}\right)\end{array}$ & $\begin{array}{l}\text { Yield strength } \\
\mathrm{f}_{\mathrm{r}}(\mathrm{MPa})\end{array}$ & $\begin{array}{l}\text { Ultimate strength } \\
\text { Fu (MPa) }\end{array}$ & $\begin{array}{l}\text { Yield } \\
\text { strain }\left(\varepsilon_{n, n}\right)\end{array}$ & $\begin{array}{l}\text { Ultimate } \\
\text { strain }\left(\varepsilon_{n}\right)\end{array}$ & Utilizations \\
\hline 10 & Deformed & 78.5 & 321 & 438 & 0.0016 & 0.0022 & Shear reinforcement and ties \\
\hline 16 & Deformed & 200.96 & 437 & 730 & 0.0021 & 0.0036 & Main reinforcement (longitudinal) \\
\hline
\end{tabular}

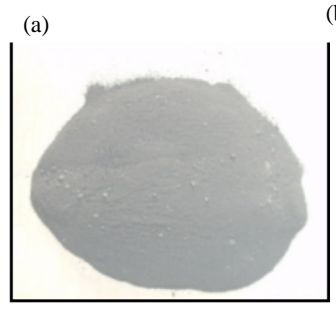

(e)

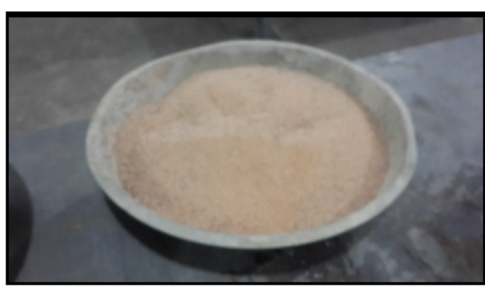

(c)

(b)
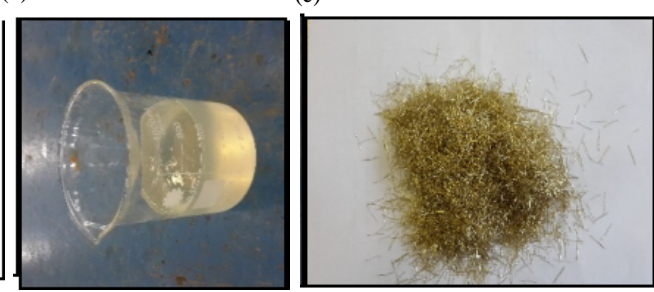

(f) (d)
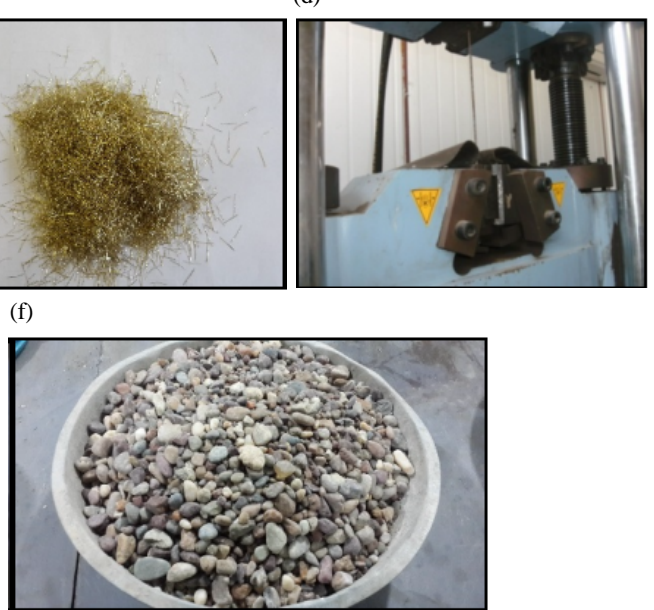

Fig. 4: a-f) Fine and coarse aggregate, silica fume, superplasticizer, steel fiber and steel reinforcement tensile testing of steel bar used in this research

(a)

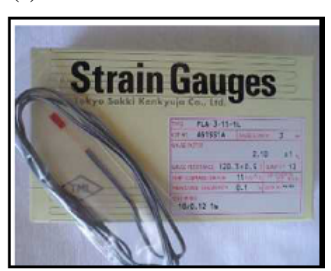

(b)

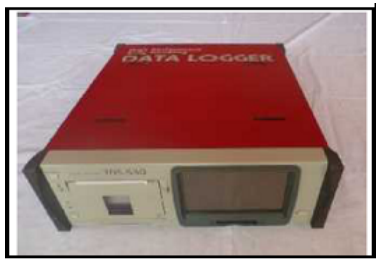

(c)

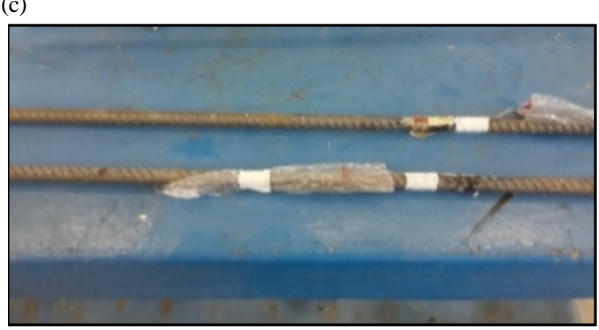

Fig. 5: a-c) Strain gauges and data logger

Reinforcing steel bars: Two sizes of deformed bars were used with properties as shown in Table 2.

Steel fibers: Steel fibers ( $\mathrm{L}=13 \mathrm{~mm}, \mathrm{~d}=0.2 \mathrm{~mm}$ tensile strength $2600 \mathrm{MPa}$, modulus of elasticity $=210 \mathrm{MPa}$ and aspect ratio $=65$ ) manufactured by Hebei Yusen Metal Wire Mesh Company Ltd. Company, China, followed to the provisions of ASTM A820 M-11. All the materials used in this research are presented in Fig. 4.

Steel strain gauges installation and measurement: One pre-wired strain measures were adopted on the shear reinforcement bars for specimens (12-14) with fiber ratios of $0,1.0$ and $2.0 \%$ to conclude the strain in the shear steel rebar at various loading steps. The total strain gauges, adhesive materials and every additional equipment were introduced from (TML Japan Company). Appropriate construction is needed to guarantee that strains on the reinforcement surface are completely transferred to the strain gauge and during gauges are bonded to reinforcement bars, preparations are important and required to preserve the installation from destruction. Data logger Model (TML/TDS-530) was adopted to estimate the strain in reinforcements as displayed in Fig. 5.

Experimental program (details of push off test specimens): The push-off test method is presented, here, for the study of shear force depends on the method of exposing the model to the external loads (axial) to produce a shear force on the surface or shear plane of the model. The main objective of this research includes a practical and theoretical study, to study the behavior and ability of the model examined in this method using different quantities and ratios of steel fiber and the exhibition to high temperatures and studies all these effects on the method of transmission of shear force in concrete sections. In this research, the work was divided into four groups of models, one of which was with the addition of the fiber and the other without fiber. The dimensions of the mold specimens were adopted by dimension $(440 \mathrm{~mm}$ height, $200 \mathrm{~mm}$ width and $100 \mathrm{~mm}$ thickness) with the 
Table 3: Details of specimens and factor affecting the shear transfer strength

\begin{tabular}{|c|c|c|c|c|c|c|c|c|c|c|}
\hline \multirow[b]{2}{*}{ Specimens } & \multirow[b]{2}{*}{$\begin{array}{l}\text { Compressive } \\
\text { strength }\end{array}$} & \multirow[b]{2}{*}{$\begin{array}{l}\text { Mix design } \\
(\mathrm{MPa})\end{array}$} & \multirow[b]{2}{*}{$\begin{array}{l}\text { Width } \\
\text { (mm) }\end{array}$} & \multirow[b]{2}{*}{$\begin{array}{l}\text { Thickness } \\
\text { (mm) }\end{array}$} & \multirow[b]{2}{*}{$\begin{array}{c}\text { Height } \\
(\mathrm{mm})\end{array}$} & \multicolumn{2}{|c|}{$\begin{array}{l}\text { No reinforcement } \\
\text { (steel fiber only) }\end{array}$} & \multirow[b]{2}{*}{$\begin{array}{c}\text { Temperature } \\
\left({ }^{\circ} \mathrm{C}\right)\end{array}$} & \multirow[b]{2}{*}{$\begin{array}{l}\text { Steel fiber } \\
\text { content } V_{f}(\%)\end{array}$} & \multirow[b]{2}{*}{$\begin{array}{l}\text { Shear transfer } \\
\text { strength (MPa) }\end{array}$} \\
\hline & & & & & & $\begin{array}{l}\rho_{\text {vfy }} \\
(\mathrm{MPa})\end{array}$ & $\begin{array}{l}\text { No. of } \\
\text { stirrup legs }\end{array}$ & & & \\
\hline 1 & 36 & 1 & 200 & 100 & 440 & - & - & 20 & 0 & 1.5 \\
\hline 2 & 41 & 2 & 200 & 100 & 440 & - & - & 20 & 1 & 2 \\
\hline 3 & 45 & 3 & 200 & 100 & 440 & - & - & 20 & 2 & 2.5 \\
\hline 4 & 36 & 1 & 200 & 100 & 440 & 3.66 & 0 & 20 & 0 & 7.2 \\
\hline 5 & 41 & 2 & 200 & 100 & 440 & 3.66 & 0 & 20 & 1 & 8.1 \\
\hline 6 & 45 & 3 & 200 & 100 & 440 & 3.66 & 0 & 20 & 2 & 8.7 \\
\hline 7 & 41 & 2 & 200 & 100 & 440 & 3.66 & 0 & 100 & 1 & 6.1 \\
\hline 8 & 41 & 2 & 200 & 100 & 440 & 3.66 & 0 & 200 & 1 & 5.7 \\
\hline 9 & 41 & 2 & 200 & 100 & 440 & 3.66 & 0 & 400 & 1 & 5.5 \\
\hline 10 & 41 & 2 & 200 & 100 & 440 & 3.66 & 0 & 600 & 1 & 4.3 \\
\hline 11 & 41 & 2 & 200 & 100 & 440 & 3.66 & 0 & 800 & 1 & 3.8 \\
\hline 12 & 36 & 1 & 200 & 100 & 440 & 3.66 & 2 & 20 & 0 & 10 \\
\hline 13 & 41 & 2 & 200 & 100 & 440 & 3.66 & 2 & 20 & 1 & 11.2 \\
\hline 14 & 45 & 3 & 200 & 100 & 440 & 3.66 & 2 & 20 & 2 & 12.3 \\
\hline 15 & 41 & 2 & 200 & 100 & 440 & 3.66 & 2 & 100 & 1 & 8.5 \\
\hline 16 & 41 & 2 & 200 & 100 & 440 & 3.66 & 2 & 200 & 1 & 8 \\
\hline 17 & 41 & 2 & 200 & 100 & 440 & 3.66 & 2 & 400 & 1 & 7.6 \\
\hline 18 & 41 & 2 & 200 & 100 & 440 & 3.66 & 2 & 600 & 1 & 6.1 \\
\hline 19 & 41 & 2 & 200 & 100 & 440 & 3.66 & 2 & 800 & 1 & 5.3 \\
\hline 20 & 36 & 1 & 200 & 100 & 440 & 7.32 & 4 & 20 & 0 & 12.5 \\
\hline 21 & 41 & 2 & 200 & 100 & 440 & 7.32 & 4 & 20 & 1 & 14 \\
\hline 22 & 45 & 3 & 200 & 100 & 440 & 7.32 & 4 & 20 & 2 & 15.4 \\
\hline 23 & 41 & 2 & 200 & 100 & 440 & 7.32 & 4 & 100 & 1 & 10.3 \\
\hline 24 & 41 & 2 & 200 & 100 & 440 & 7.32 & 4 & 200 & 1 & 9.4 \\
\hline 25 & 41 & 2 & 200 & 100 & 440 & 7.32 & 4 & 400 & 1 & 8 \\
\hline 26 & 41 & 2 & 200 & 100 & 440 & 7.32 & 4 & 600 & 1 & 7.6 \\
\hline 27 & 41 & 2 & 200 & 100 & 440 & 7.32 & 4 & 800 & 1 & 6.4 \\
\hline
\end{tabular}

(a)

(b)

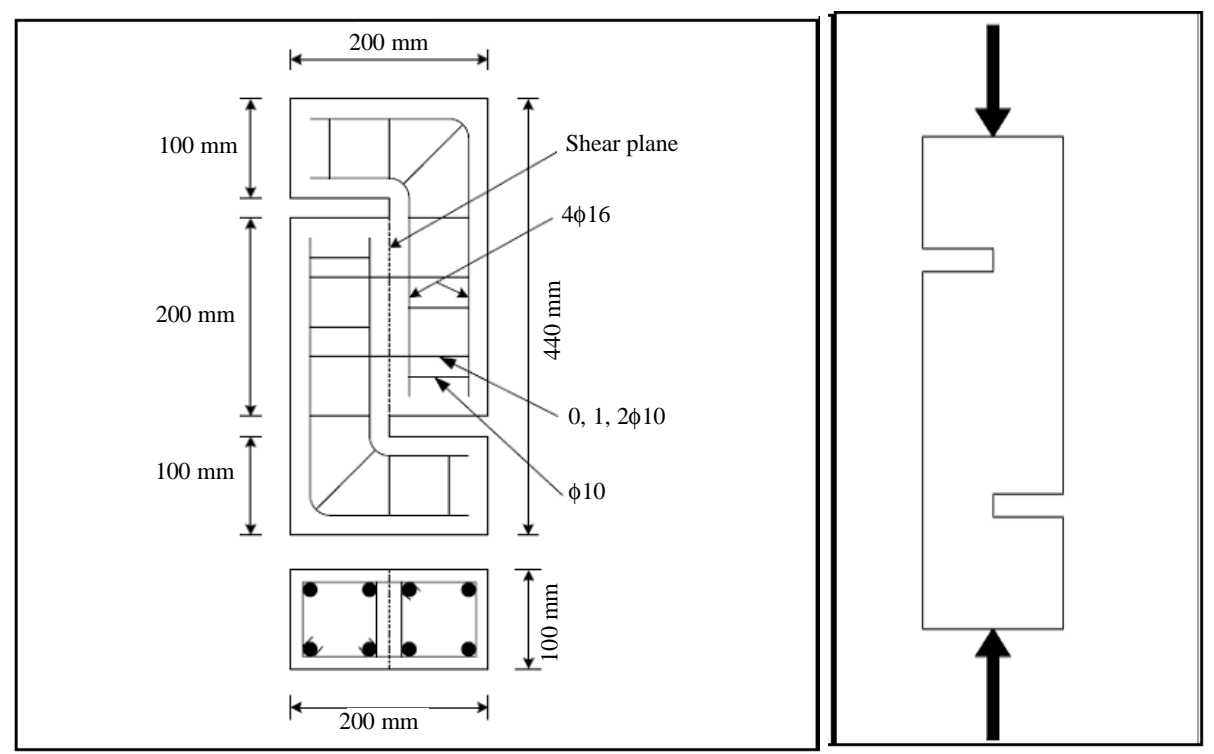

Fig. 6: a, b) Details of push-off test specimens, reinforcement position and loading type (all dimensions are in mm)

shear failure plane of $200 \mathrm{~mm}$ as shown in Fig. 6. The shear reinforcement and fiber volume fraction for all groups of concrete specimens are given in Table 3. Plywood and steel molds were prefabricated to cast all the specimens. After pouring and casting the samples and after one day from casting, the specimens were put in water for 28 days to complete the hydration process, the molds then were removed and waiting for drying and then placed in the electric ovens and subjected to different temperatures. The models were heated with a slow 
Table 4: Concrete mechanical properties and percentage increase in compressive strength, splitting tensile strength, modulus of rupture and modulus of elasticity

\begin{tabular}{|c|c|c|c|c|c|c|c|c|c|}
\hline Mix & $\begin{array}{l}\text { Steel fiber } \\
\text { content }(\%)\end{array}$ & $\begin{array}{l}\text { Compressive } \\
\text { strength } \\
\text { (MPa) }\end{array}$ & $\begin{array}{l}\text { Percentage } \\
\text { increase } \\
\text { compressive } \\
\text { strength (\%) }\end{array}$ & $\begin{array}{l}\text { Modulus } \\
\text { of rupture } \\
(\mathrm{MPa}) \\
\end{array}$ & $\begin{array}{l}\text { Percentage } \\
\text { increase } \\
\text { modulus of } \\
\text { rupture }(\%)\end{array}$ & $\begin{array}{l}\text { Splitting } \\
\text { tensile } \\
\text { strength } \\
(\mathrm{MPa}) \\
\end{array}$ & $\begin{array}{l}\text { Percentage increase } \\
\text { splitting tensile } \\
\text { strength }(\%)\end{array}$ & $\begin{array}{l}\text { Modulus of } \\
\text { elasticity } \\
(\mathrm{MPa})\end{array}$ & $\begin{array}{l}\text { Percentage } \\
\text { increase } \\
\text { modulus of } \\
\text { elasticity }(\%)\end{array}$ \\
\hline 1 & 0 & 36 & -- & 5.5 & --- & 3.7 & -- & 24000 & ---- \\
\hline 2 & 1 & 41 & 13.8 & 9.5 & 72.7 & 5.3 & 43.2 & 27000 & 12.5 \\
\hline 3 & 2 & 45 & 25 & 12 & 118.18 & 5.8 & 56.75 & 28500 & 18.75 \\
\hline
\end{tabular}
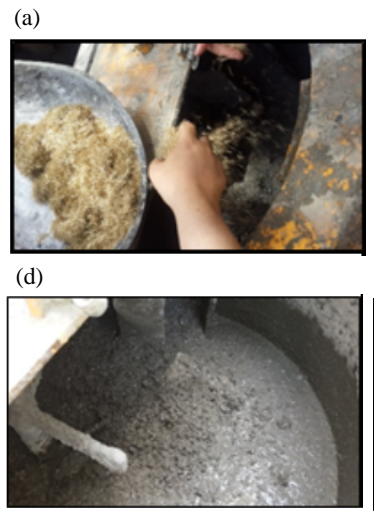

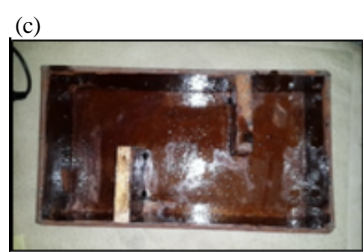

(f)

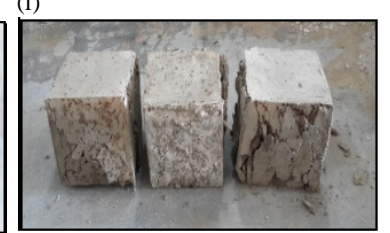

Fig. 7: a-f) Mixing process

process at the constant rate of $2^{\circ} \mathrm{C} / \mathrm{min}$ to avoid severe and high-temperature thermal gradients. After the ovens were reaches to the desired thermal level, the ovens were closed, then the ovens were opened and the samples were transferred to the loading test equipment.

Mixing procedures and tests of fresh concrete: The self-compacted design mix should provide all the criteria for the production of self-compacted concrete with the best ability to filling and resistance to separation. Accordingly, trial mixes are arranged to achieve a satisfying SCC mix by evaluating fresh concrete tests. Procedure for the mixing method was as regards, mixing the dry materials ingredients (cement, sand, gravel and silica fume) for sufficient time. Then combining superplasticizer and mixing with the water and then introduce to the mixer while it works. The fresh concrete was then mixed for sufficient time.

Fiber then added to the mixer and distributed by hand to avoid gathering of fiber. After all fiber quantity is added to the mixer the fresh concrete is mixed very well to gain a homogenous concrete.

Molds, casting and curing loading setup and measurements: Before starting the casting process, some arrangements are needed at first. First, clean all the molds and then collect, arrange and tie them well to ensure that they do not open during casting and then lubricate their parts and internal surfaces to avoid adhesion and hardening of the concrete on the surface to make it easier to use and pour again. After that all the parts of the reinforcing steel are connected and then placed inside the molds in their correct positions. After the completion of the arrangement of the molds and reinforcing steel, the concrete is mixed and then poured into the molds without the need for external vibrators because it is a self-compacted concrete that depends on the casting on its weight only, filling the molds smoothly and easily and interfering between reinforcing steel without any separation or clogging. After completion of the casting process, all models should be covered with plastic or nylon sheet to ensure concrete reaction and ensure that water evaporation is prevented from the concrete to reduce the cracks caused by the loss of water causing the shrinkage of the concrete. After 1 day of the casting process, the samples are taken and transferred to the water tanks after coding and numbered according to the type of concrete mix and placed for 28 days to complete the process of hydration of the concrete and complete curing. After completing 28 days, the sample shall be taken out, dried and then dyed to distinguish the cracks in the concrete. The molds are placed in the laboratory and waiting until the test day. They are placed vertically on the loading devices and then exposed to loads that are loaded from the top and the support is from the bottom of the model. Loads are increased in equal values until, the final load is reached. Figure 7 Presented mixing process and mold shape.

Details of the mechanical properties of self-compacting concrete in hardened state: Table 4 and 5 and (Fig. 8-15) summarizes the results of mechanical properties of SCC 


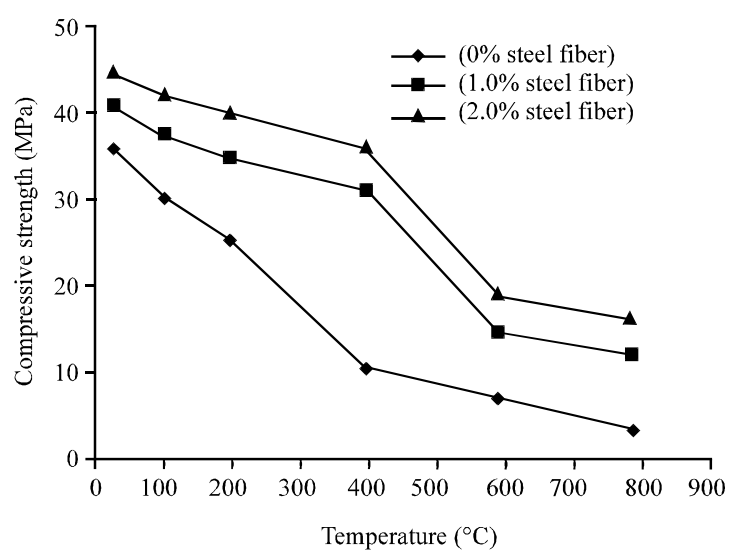

Fig. 8: Effect of steel fiber content on compressive strength

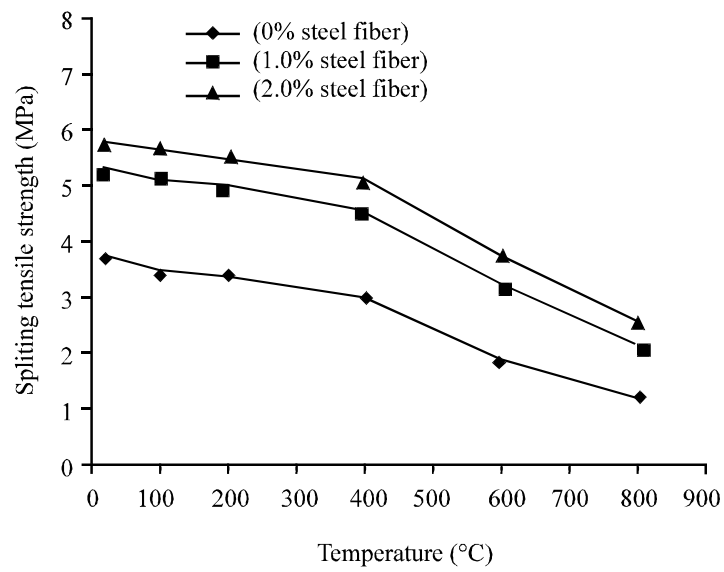

Fig. 9: Effect of steel fiber content on splitting tensile strength

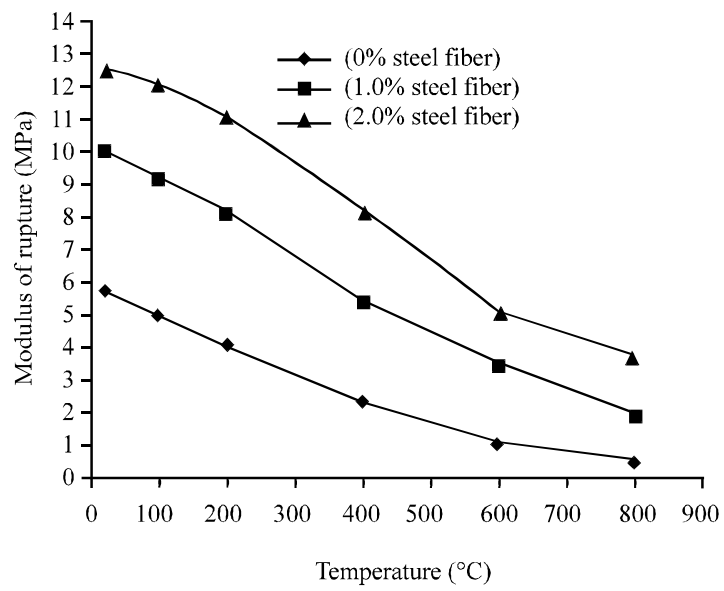

Fig. 10: Effect of steel fiber content on modulus of rupture

which has been obtained for different mixes at age of 28 days. This table is based on the average values of

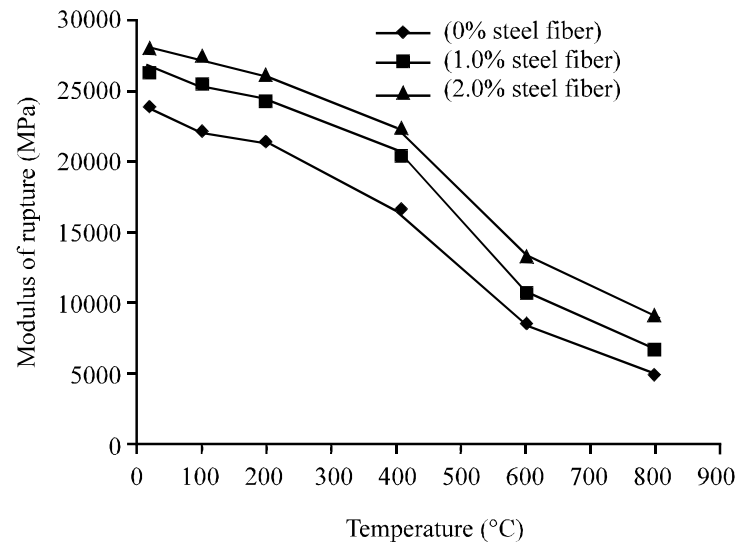

Fig. 11: Effect of steel fiber content on modulus of elasticity

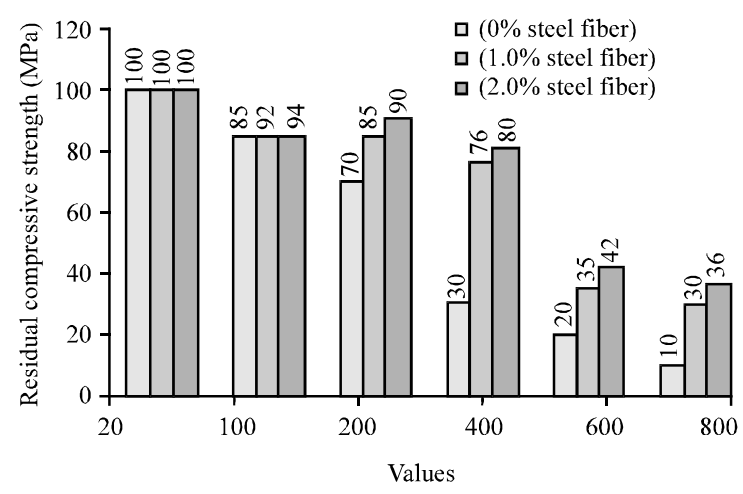

Fig. 12: Percentage decreasing in compressive strength

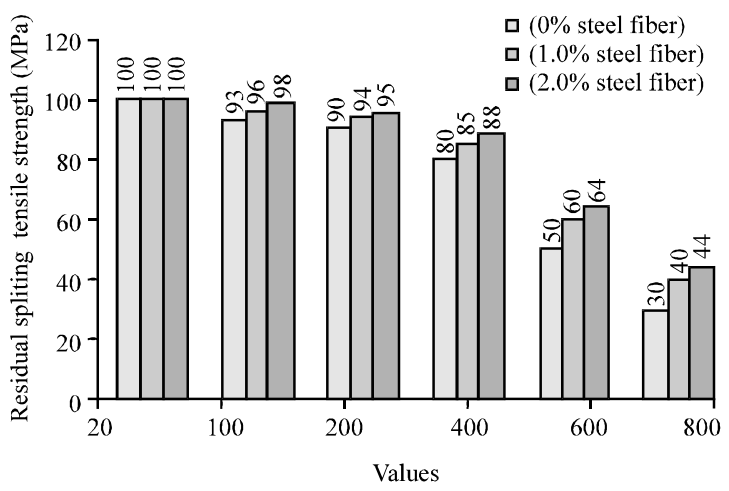

Fig. 13: Percentage decreasing in splitting tensile strength

three tests for three models. The conduct of concrete in the solid state (hardened) and its properties is a good indicator and the first step to study the behavior and characteristic of concrete. In this research, electric furnaces that have the ability to reach high temperatures have been used. The specimens were exposed to different temperatures of $100,200,400,600$ and $800^{\circ} \mathrm{C}$ ). Each 
Table 5: Percentage decreasing in concrete properties after exposure to heat for compressive strength, splitting tensile strength, modulus of rupture and modulus

\begin{tabular}{|c|c|c|c|c|c|c|c|c|}
\hline $\begin{array}{l}\text { Mix/Temperature } \\
\left({ }^{\circ} \mathrm{C}\right)(\%)\end{array}$ & $\begin{array}{l}\text { Compressive } \\
\text { strength } \\
\text { (MPa) }\end{array}$ & $\begin{array}{l}\text { Percentage } \\
\text { decrease } \\
\text { compressive } \\
\text { strength (\%) }\end{array}$ & $\begin{array}{l}\text { Modulus of } \\
\text { rupture } \\
(\mathrm{MPa})\end{array}$ & $\begin{array}{l}\text { Percentage } \\
\text { decrease } \\
\text { Modulus of } \\
\text { rupture (\%) }\end{array}$ & $\begin{array}{l}\text { Splitting } \\
\text { tensile } \\
\text { strength } \\
\text { (Mpa) } \\
\end{array}$ & $\begin{array}{l}\text { Percentage decrease } \\
\text { splitting tensile } \\
\text { strength (\%) }\end{array}$ & $\begin{array}{l}\text { Modulus of } \\
\text { elasticity } \\
\text { (MPa) }\end{array}$ & $\begin{array}{l}\text { Percentage } \\
\text { decrease } \\
\text { modulus of } \\
\text { elasticity }(\%)\end{array}$ \\
\hline \multicolumn{9}{|l|}{ Mix 1} \\
\hline 20 & 36.0 & 100 & 5.500 & 100 & 3.7 .0 & 100 & 24000 & 100 \\
\hline 100 & 30.6 & 85 & 4.675 & 85 & 3.441 & 93 & 22560 & 94 \\
\hline 200 & 25.2 & 70 & 3.850 & 70 & 3.330 & 90 & 21600 & 90 \\
\hline 400 & 10.8 & 30 & 2.200 & 40 & 2.960 & 80 & 16800 & 70 \\
\hline 600 & 7.2 & 20 & 1.100 & 20 & 1.850 & 50 & 8400 & 35 \\
\hline 800 & 3.6 & 10 & 0.550 & 10 & 1.110 & 30 & 4800 & 20 \\
\hline \multicolumn{9}{|l|}{ Mix 2} \\
\hline 20 & 41.00 & 100 & 9.500 & 100 & 5.300 & 100 & 27000 & 100 \\
\hline 100 & 37.72 & 92 & 8.740 & 92 & 5.088 & 96 & 25920 & 96 \\
\hline 200 & 34.85 & 85 & 7.790 & 82 & 4.982 & 94 & 24840 & 92 \\
\hline 400 & 31.16 & 76 & 5.225 & 55 & 4.505 & 85 & 21060 & 78 \\
\hline 600 & 14.35 & 35 & 3.325 & 35 & 3.180 & 60 & 10800 & 40 \\
\hline 800 & 12.30 & 30 & 1.900 & 20 & 2.120 & 40 & 6750 & 25 \\
\hline \multicolumn{9}{|l|}{ Mix 3} \\
\hline 20 & 45.0 & 100 & 12.00 & 100 & 5.800 & 100 & 28500 & 100 \\
\hline 100 & 42.3 & 94 & 11.52 & 96 & 5.684 & 98 & 27930 & 98 \\
\hline 200 & 40.5 & 90 & 10.56 & 88 & 5.510 & 95 & 26505 & 93 \\
\hline 400 & 36.0 & 80 & 7.80 & 65 & 5.104 & 88 & 22800 & 80 \\
\hline 600 & 18.9 & 42 & 4.80 & 40 & 3.712 & 64 & 13680 & 48 \\
\hline 800 & 16.2 & 36 & 3.60 & 30 & 2.552 & 44 & 9120 & 32 \\
\hline
\end{tabular}

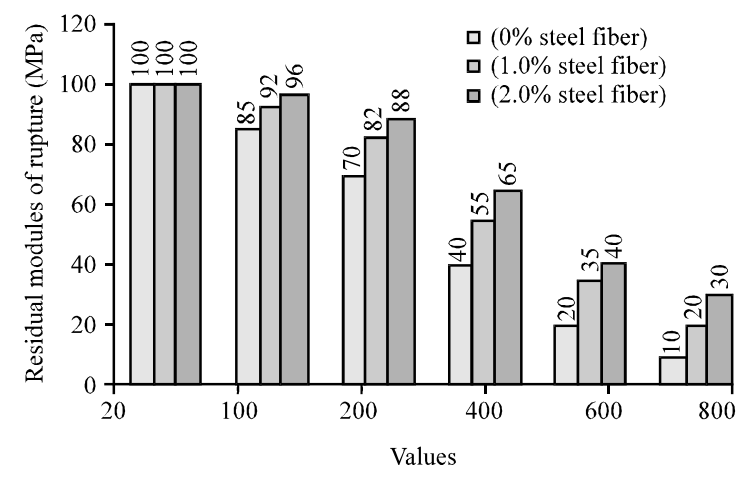

Fig. 14: Effect of fiber content on modulus of rupture

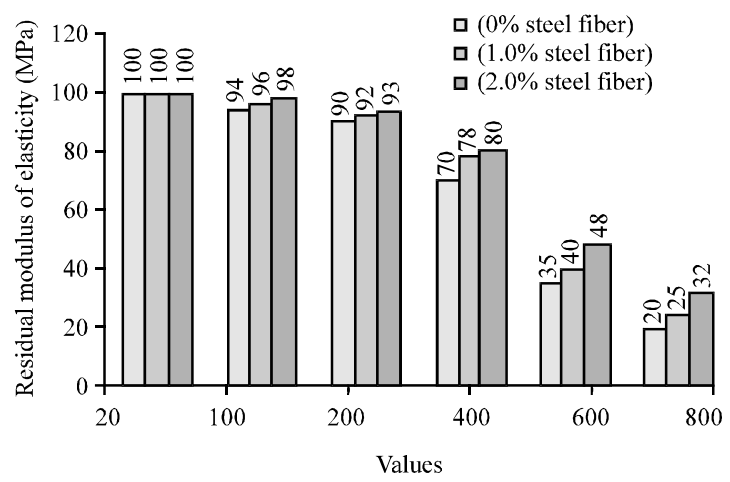

Fig. 15: Percentage decreasing in modulus of elasticity

specimen is heated to the required temperature which must be tested on the basis, the specimen should and allowed to stay in the oven for a full hour and then the furnaces are turned off but not allowed to open due to fear of exposure to high and dangerous temperatures. After some time, the ovens will be cool enough and then the ovens are opened and the samples removed waiting for the testing process.

The use and increase of steel fiber in the concrete mix of self-compacted concrete are improved the concrete properties and characteristic that resulting from the practical research as the results indicated in the drawings and tables which causes a clear improvement and increase in the strength of the concrete, bending, tensile and shear. The increase in the properties of concrete can be divided and attributed to two important factors; first, the correct distribution of steel fiber inside the concrete mix to ensure that they are not collected leading to formulate as a strong matrix that increases the hardness and integrity of the concrete. The second reason is the due development in post cracking ductility related to a decrease in cracking and the style of failure in SFRCC as correlated to traditional SCC. Though, steel fibers created crack closing forces which commenced to further developing in concrete strength. This performance is essentially connected to the performance of steel fibers in producing fracture energy around crack tips which is expected to extent crack arising by transporting it from individual side to the opposite. The results reveal a significant reduction in compressive strength, flexural and splitting tensile after exposure to a temperature varying within $\left(100-800^{\circ} \mathrm{C}\right)$ of plain and steel fiber reinforced concrete but the decline in total mechanical characteristics for SFRSCC is lower comparable to plain concrete following the exposure to higher temperature. 
(a) (b)

(c)

(d)

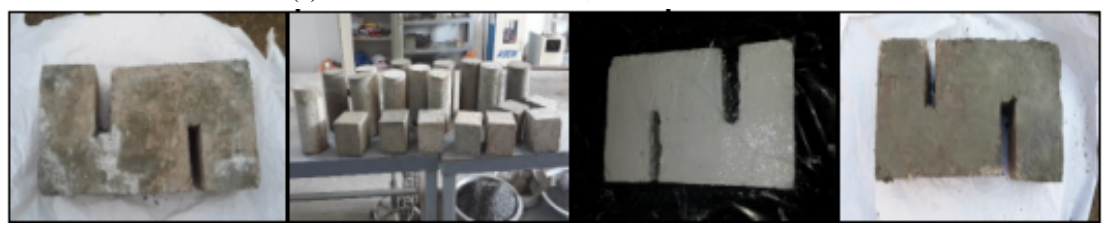

(e)

(f)

(g)

(h)

(i)

(j)

(k)

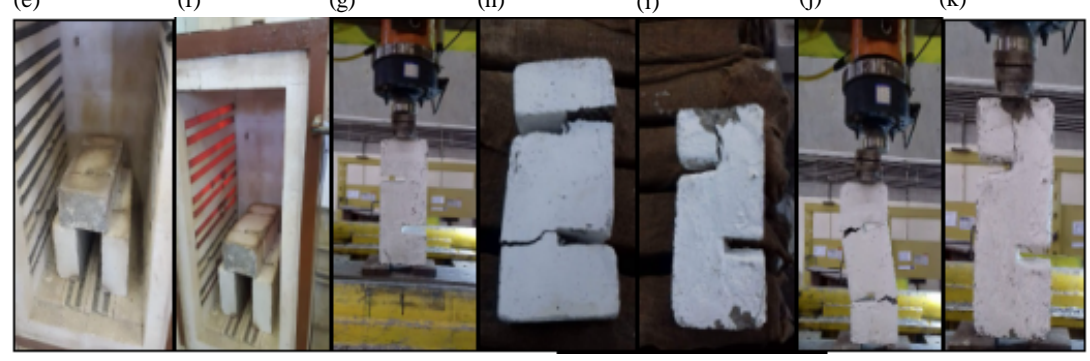

(1)

(m)

(n)

(o)

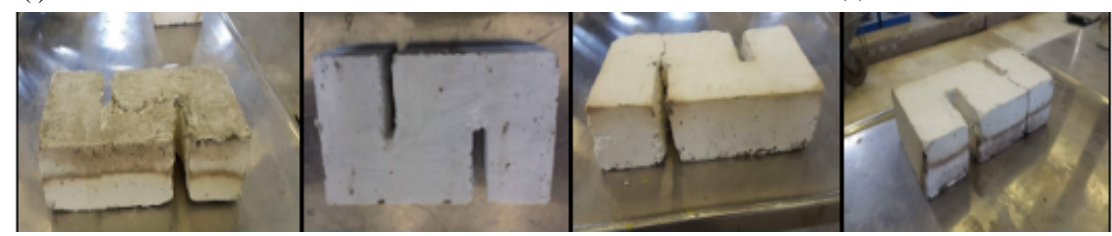

(p)

(q)

(r)

(s)

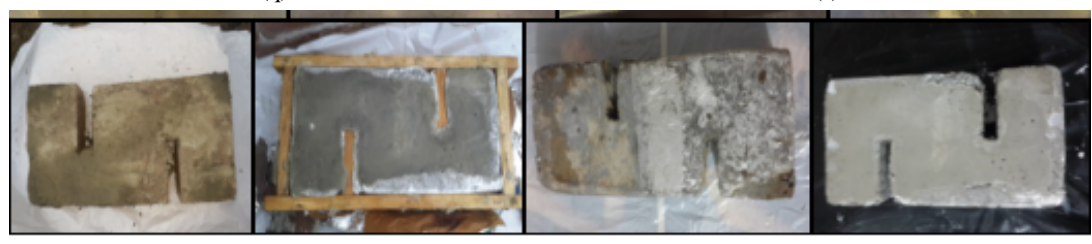

Fig. 16: a-s) Mechanical properties tests and modes of failure and cracking shapes of push-off specimens

Mode of failure and crack patterns: In this experimental investigation, 27 specimens were examined. These specimens are indistinguishable in size but varying in concrete strength, fiber volume fraction and the ratio of steel reinforcement. Relating to certain variables, ultimate loads, crack patterns with the inclusion of modes of failure are variables. For the unreinforced specimens, the specimens declined by compression failure or cracks parallel or forward the shear plan developed at moderate loads, the certain cracks were supplemented with several and short diagonal tension cracks in individual specimens because load raised those cracks generated to create continuous cracks adjacent the shear plane while for the reinforced specimens during the load was employed to the specimens, minor cracking at the shear region were developed. When the load increased, cracks become wider for the fiber specimens, the crack did not open widely, since, the extension of the crack was captured by the fibers. In fact, the mode of the orientation of fibers has a meaningful effect on the extension of the crack. If the fibers are oriented away from the direction of the principal tensile stress then the load carried by the fiber will not be aligned with its longitudinal axis and hence, the load carried by the fiber can be decomposed into two orthogonal components. One of them was aligned with fiber longitudinal axis and acted as a pull cut force while the other acted as a normal force on the fiber axis. The latter component will initiate a friction force between the fiber and the matrix along the fiber axis. Figure 16 shows the failure and cracks patterns of the push-off specimens. For the specimens subjected to high temperature, the test realizes a proximity of many thermal cracks parallel to the shear plan and across it related to the heating manner began to develop and generate many longitudinal shear cracks within the shear plane after subjected to loads alternately of generated just one connected crack and to further concrete compression cracks adjacent to shear failure surface.

Nonlinear finite element modeling (ANSYS): The nonlinear finite element method has recommended within the civil engineering technology and the demand for effective program substituting for the experimental research. 
(a)

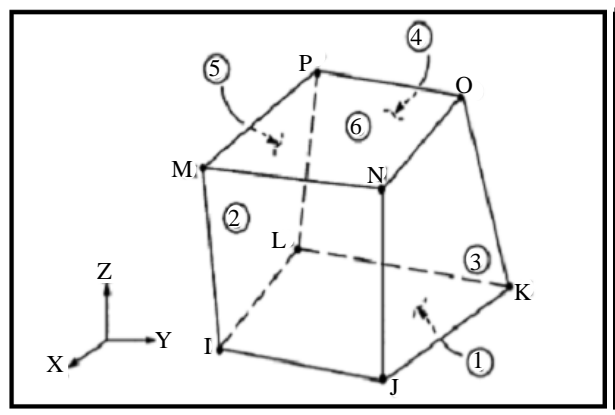

(b)

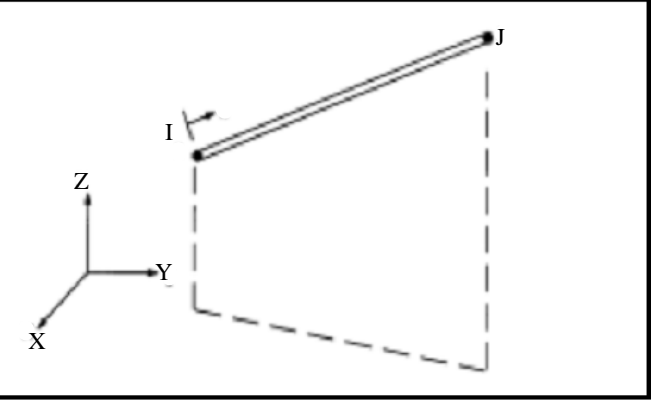

Fig. 17: a, b) Brick element (solid 65) for plain concrete and link 180 for steel rebars

(a)

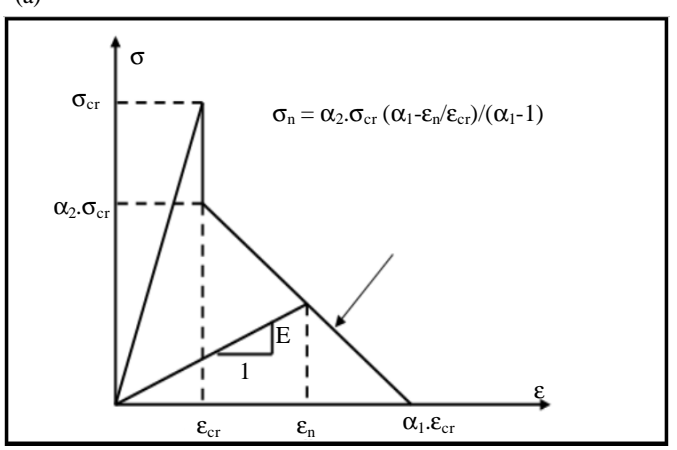

(b)

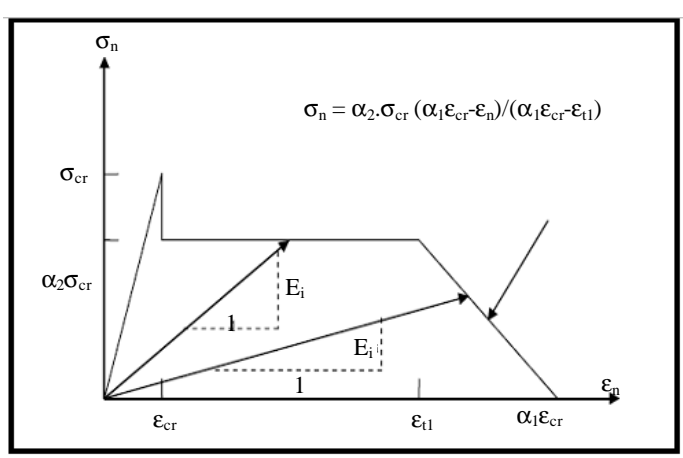

Fig. 18: a, b) Post-cracking model of conventionally reinforced concrete (TS1) and post-cracking model of steel fiber reinforced concrete (TS2)

It employed for investigating several reinforced concrete members. This program introduces many complete and useful information which applied for the analysis of shear strength specimens by the push-off test operating the (ANSYS Software) then later comparing the theoretical results with the experimental one which proved the satisfactory agreement. SOLID65 with eight-node isoparametric brick elements were employed to describe concrete and Link180 elements applied to design the embedded reinforcement bar as shown in Fig. 17. Non-linear behavior in compression, tension and shear modulus was taken into consideration for fibrous concrete. The compression performance of concrete is reproduced by an elasto-plastic work accompanied by a perfectly plastic response which is discontinued at the onset of crushing.

The released tensile stresses perpendicular to the plane of cracks are characterized by an ordinary stress-strain curve. In the current investigation, an adoption of the tension-stiffening model theory is presented. This has been performed in ANSYS by allowing continuous release of the concrete stress perpendicular to the cracked plane. Two models were employed here to account for tension-stiffening effect as shown in Fig. 18. The model designated TS1 is suitable for analyzing specimens without fibers while Model TS2 is suitable for analyzing fiber specimens. The finite element solutions results show that ultimate load achieved applying Model TS2 is close to experimental load responses.

Element meshing, loads and boundary conditions and analysis: Figure 19 present the mesh representation of the push-off specimens, the process of applying the loads on the specimens and the boundary conditions. After providing the total information data of material and geometrical characteristics, the specimens were distributed within elements, reinforced with longitudinal and lateral (Ties) reinforcement. Boundary provisions are required to be implemented wherever the existing of supports and loadings to guarantee that the model performs as the identical procedure for the experimental specimens. Specimens (No. 12) were taken as examples for ANSYS work. Table 6 shows the correlation of the finite element results with the laboratory results of shear strength for the push-off examples. The numerical results 
(a)

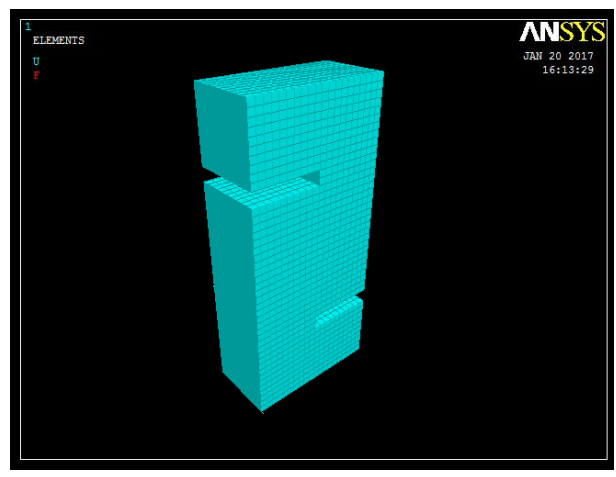

(c)

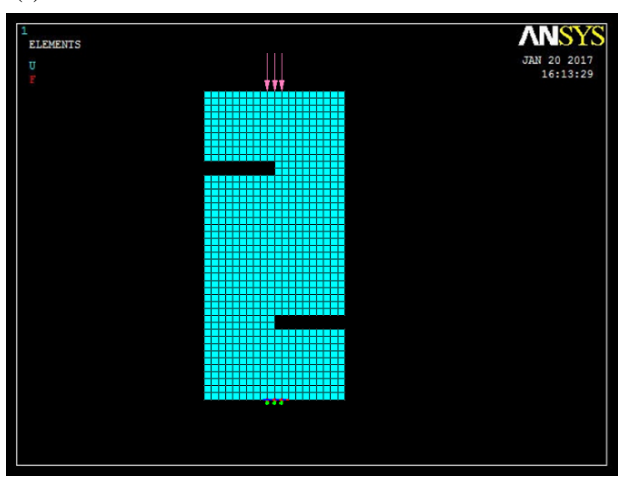

(b)

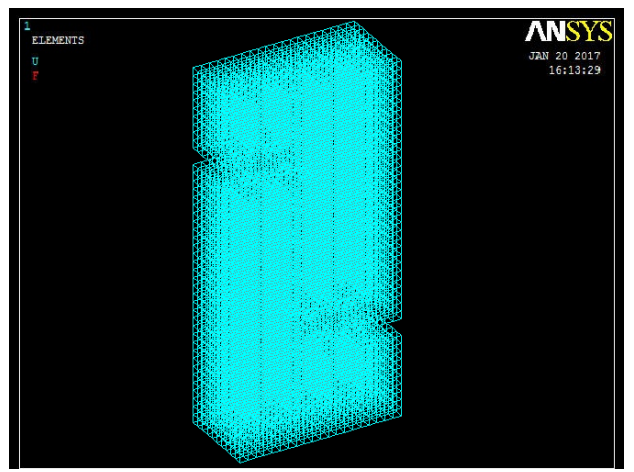

(d)

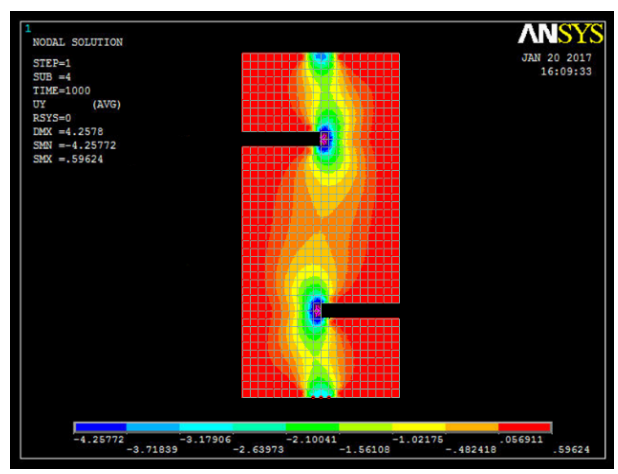

Fig. 19: a-d) Modeling of specimens, boundary conditions, loadings and meshing and stress diagram

Table 6: Comparisons between experimental, FEM and others equations

\begin{tabular}{|c|c|c|c|c|c|c|c|c|c|c|}
\hline Specimens & $\mathrm{f}_{\mathrm{c}}(\mathrm{MPa})$ & Mix & $\rho_{\mathrm{fy}}(\mathrm{MPa})$ & Temp. $\left({ }^{\circ} \mathrm{C}\right)$ & $V_{f}(\%)$ & $\begin{array}{l}\text { Exp. Shear transfer } \\
\text { strength (MPa) }\end{array}$ & $\begin{array}{l}\text { Ridha et d. } \\
\text { (2012) }\end{array}$ & $\begin{array}{l}\text { Al-Obidid } \\
(1998)\end{array}$ & FEM & $\begin{array}{l}\text { Proposed } \\
\text { equation }\end{array}$ \\
\hline 4 & 36 & 1 & 3.66 & 20 & 0 & 7.2 & 3.06 & 3.57 & 6.912 & 3.4776 \\
\hline 5 & 41 & 2 & 3.66 & 20 & 1 & 8.1 & 6.106192 & 6.669859 & 7.533 & 5.8989 \\
\hline 6 & 45 & 3 & 3.66 & 20 & 2 & 8.7 & 7.356357 & 9.711381 & 7.917 & 8.2236 \\
\hline 12 & 36 & 1 & 3.66 & 20 & 0 & 10 & 7.062639 & 6.7176 & 9.6 & 6.6069 \\
\hline 13 & 41 & 2 & 3.66 & 20 & 1 & 11.2 & 10.10883 & 9.817459 & 10.08 & 9.0282 \\
\hline 14 & 45 & 3 & 3.66 & 20 & 2 & 12.3 & 11.359 & 12.85898 & 11.562 & 11.3529 \\
\hline 20 & 36 & 1 & 7.32 & 20 & 0 & 12.5 & 9.384501 & 9.8652 & 12 & 9.7362 \\
\hline 21 & 41 & 2 & 7.32 & 20 & 1 & 14 & 12.43069 & 12.96506 & 12.88 & 12.1575 \\
\hline 22 & 45 & 3 & 7.32 & 20 & 2 & 15.4 & 13.68086 & 16.00658 & 14.322 & 14.4822 \\
\hline
\end{tabular}

revealed much great complying with the test results for each specimen. Figure 19 shows the shear stress distribution across failure plain. Figure 19 shows that the shear stresses are concentrated near the shear zone boundaries and decreased toward the center of the shear plane.

\section{RESULTS AND DISCUSSION}

Push-off specimens tests: The shear strength transfer may be described as the ultimate shear stress that the concrete sections can handle through the loading stages. The shear transfer within the shear plane may be represented with the maximum force transmitted by the section shared by the domain of the shear plane. In this investigation, the shear stress may be explained as the total axial load on the $(200 \times 100 \mathrm{~mm})$ which is the shear failure plane area. An increasing in ultimate load was recognized, this development is related to the introduction of SFRC and the ability of steel fibers to prevent cracking and control propagation which generated an improvement in the load transmitting capability. The specimens with the higher portion content of fibers provided a greater strength and improvement in the ultimate capacity related to the presence of steel fibers in the concrete mixture. The (push-off) shear test of the steel fiber self-compacted concrete proved that experimental specimen's shear stress improved with the incorporation of high reinforcement ratio. The experimental results observed that the steel fiber molds have achieved minor strain amount than the 


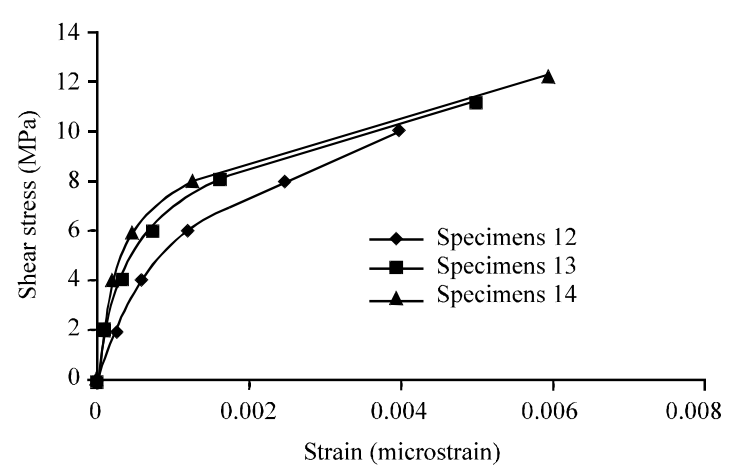

Fig. 20: Effect of steel fiber content on load-strain relation of specimens 12,13 and 14; Effect of steel fiber content (0-1.0-2\%) on shear strength (MPa)-strain

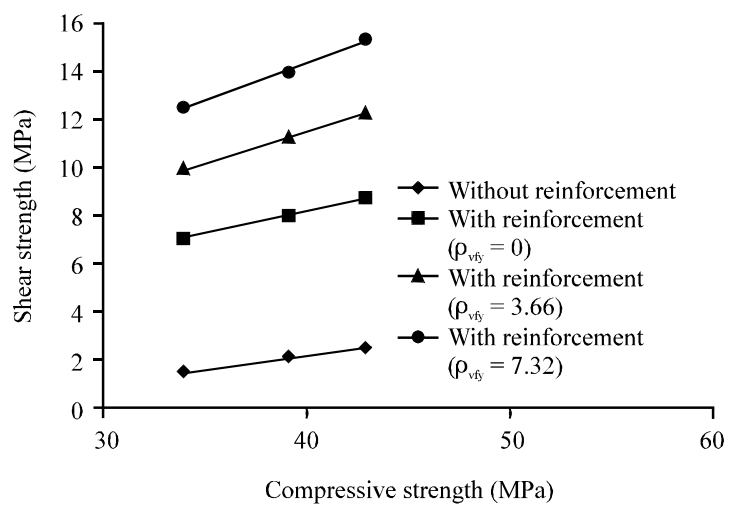

Fig. 21: Comparison between compressive strength and shear strength for various reinforcement ratio and fiber contents at $20^{\circ} \mathrm{C}(0,1.0$ and $2.0 \%$ steel fiber $)$

non-steel fiber when subjected to the same loading, this improvement in reducing the concrete strain is related and attached to the effective impact of steel fiber in concrete. Raising the applied load amount produced improvements in the strain states of steel fiber specimens. This can be connected to the greater action of steel fibers. The influence impact of steel fibers was apparent following the generation of the cracks. Figure 20 shows the load-strain diagram. It reveals that the yielding point of the steel reinforcement enhanced during steel fiber was combined with the compound. That may be related to the bridging and restraining influence of the steel fibers to the composite.

\section{Effects of the adopted parameters}

Effect of elevated temperature: Figure 21 and 22 display and illustrate the shear transfer stresses of the concrete specimens examined by push-off test method which subjected to different temperatures. The results can be

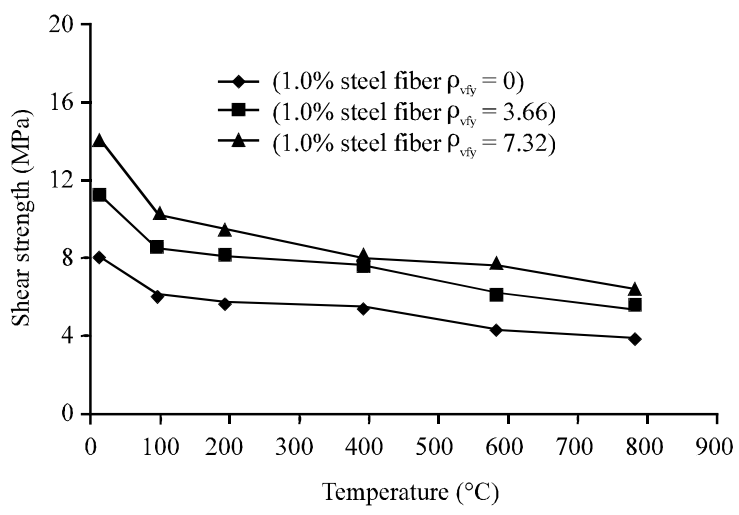

Fig. 22: Comparison between temperature and shear strength for $1.0 \%$ steel fiber and various reinforcement ratio

deduced from the drawings as they illustrate the effect of increasing temperature where the results showed a decrease in the shear strength of the specimens due to exposure to rising heat. The decrease in the shear strength of the specimen's model can be explained under the influence of many factors as it may be due to changes in concrete due to the chemical and physical effects when exposed to high temperatures or loss of moisture inside the concrete which is excessive or which does not need to complete the process of hydration causing contraction in concrete which results in internal strain that cause damage and weak in the strength of concrete sections. The other causes of the deterioration of concrete are the increase in the volume of coarse aggregates and the increase in shrinkage of the cement paste. These changes cause reactions within the concrete, causing changes due to movement either due to shrinkage or expansion causing movement in different directions which lead to the deterioration of the bond between all components of concrete in terms of fine, coarse aggregate and cement. The loss of water needed by the concrete to complete the process of hydration causes pressure on the internal pores walls as well as changes due to chemical and physical reactions, all of which lead to the deterioration and weakness of concrete which is the main cause of concrete cracks.

Effect of shear reinforcement and steel fiber: This research is based on the study of the effect of temperature, the effectiveness of steel fiber and the ratio of steel reinforcement used and their effect together with self-compacted concrete. This study shows that through the practical study and from the results obtained, 
increasing the amount of steel reinforcement ratio leads to increase the shear stress transmitted through concrete. One of the reasons that can be explained by this result is the strength of the bond between reinforcing steel and concrete as this reinforcement passes through the shear plane area which prevents, reduce or restrict the appearance of the shear cracks and increase the tolerance of concrete sections when exposed to shear forces. Reinforcement steel shows weakness when exposed to concrete under temperature effect due to changes in chemical and physical properties. The results show that the transferred shear stress is greater when the reinforcement ratios are high. On the other hand it is noticed that using steel fibers in combination with reinforcing steel bars can result in further improvement in shear strength of push-off specimens. Examination results of this investigation verify that steel fibers significantly increase shear capacity of concrete especially when it works in combination with conventional stirrups. Also, it confirms that steel fibers can replace a part of steel stirrups reaching moderately higher shear stresses at failure and improving crack propagation resistance showing higher ductility at failure. However, the steel reinforcement can be placed and distributed in the required orientations and spaced in the required distances to withstand the design loads while this cannot be ensured when steel fibers are used instead, since, steel fibers are randomly distributed in the concrete matrix and spread in different positions and orientations which lead to the conclusion that steel fibers cannot be used simply in place of conventional steel bars it can be used in compound with steel bars to increase concrete ductility, help to keep the crack as small as possible and improve the shear capacity of concrete members.

Comparison of the experimental study results with others equations for shear strength prediction: When comparing the maximum shear resistance obtained from the experimental test with their equations, differences appear. A review of some codes equations and from other researchers is given, here, RILEM relation commonly applied to estimate tensile resistance in concrete employing splitting tests Eq. 1:

$$
\mathrm{f}_{\mathrm{ctsp}}=\frac{2}{\pi} * \frac{\mathrm{F}}{\mathrm{I} . \mathrm{d}}[\mathrm{N}]
$$

Where:
$\mathrm{F}=$ Applied Force
$1=$ Length of specimen
$\mathrm{d}=$ Height of shear zone

ACI relation for shear friction. Related to the case that the elements were monolithically cast, the formula was utilized considering the friction coefficient, $\mu=1.4$ Eq. 2 :

$$
\mathrm{V}_{\mathrm{u}}=\varnothing \cdot \mathrm{A}_{\mathrm{v}} \cdot \mathrm{f}_{\mathrm{y}} \cdot \mu
$$

Where:

$\phi=0.75$

$\mu=$ Friction coefficient

$\mathrm{A}_{v}=$ Area of reinforcement crossing the shear plane

$\mathrm{f}_{\mathrm{y}}=$ Characteristic yield strength of reinforcing steel

Al-Obidid (1998) examined the fibrous high strength concrete subjected to direct shear. Depending on the results from experimental test a practical equation was generated for normal and high strength concrete with or without fiber for direct shear strength Eq. 3:

$$
\mathrm{V}_{\mathrm{u}}=\varnothing\left(\mathrm{fc}^{0.5}+0.86^{*} \rho_{\mathrm{v}} \mathrm{f}_{\mathrm{y}}+8.8 \mathrm{~F}\right)
$$

Where:

$$
\begin{aligned}
\phi= & 0.85 \\
\rho_{v}= & A v f / b h \\
F= & \left(\mathrm{L}_{\mathrm{f}} / \mathrm{D}_{\mathrm{f}}\right) \mathrm{V}_{\mathrm{f}} \mathrm{B}_{\mathrm{f}} \\
\mathrm{A}_{\mathrm{vf}}= & \text { Area of shear-friction reinforcement }\left(\mathrm{mm}^{2}\right) \\
\mathrm{bh}= & \text { Area of shear-friction plane }\left(\mathrm{mm}^{2}\right) \\
\mathrm{B}_{\mathrm{f}}= & \text { The bond factor used for bond characteristics of } \\
& \text { the fibers }
\end{aligned}
$$

Based on a large experimental of pullout tests by others researchers, $B_{f}$ was assigned a relative value of 0.5 for round fibers, 0.75 for crimped fibers and 1.0 for indented fibers.

Ridha et al. (2012) modified Al-Obidi equation to predict the of FRHPC shear strength within $\left(40<\mathrm{f}^{\prime} \mathrm{c}<107\right.$ $\mathrm{MPa}$ ) with and without shear reinforcement $\rho_{\mathrm{vfy}}$ Eq. 4:

$$
\begin{gathered}
\varphi=0.85 \text { and } F=\left(L_{f} / D_{f}\right) V_{f} B_{f} \\
V_{u}=\varnothing\left(0.1^{*} \mathrm{fc}^{0.5}+2 * \rho_{v} f_{y}^{0.66}+5 F^{0.43}\right)
\end{gathered}
$$

Kumar et al. (2015) predicted an equation for the direct shear strength with many concrete mixes, like steel fiber concrete, ordinary Strength Concrete (NSC), Self-Compacting and High Strength Concrete (SCC and HSC) Eq. 5:

$$
\mathrm{V}_{\mathrm{u}}=\left(0.123 * \mathrm{SF}^{\left.0.2608 * \mathrm{f}_{\mathrm{c}}^{1.248} * \mathrm{~W}_{\mathrm{cr}}^{0.259}\right)}\right.
$$

Proposed expression and evaluation of experimental results and influence of major parameters: An effort is performed to generate a regression equation with 
variables (fibers factor, compressive strength, ratio of reinforcement perpendicular to shear plane $\rho_{v} f_{y}$ ) and shear stress by using (data-fit program). The 133 push-off test results range between (32-107) from this research and many researcher's results were taken to evaluate the equation. The estimated shear stresses from the equations and the experimental shear stress and others formulas are plotted as presented in Fig. 23-25. Figure 26 shows data fit regression analysis and residual normal probability. Table 6 shows comparisons between experimental, FEM and others equations:

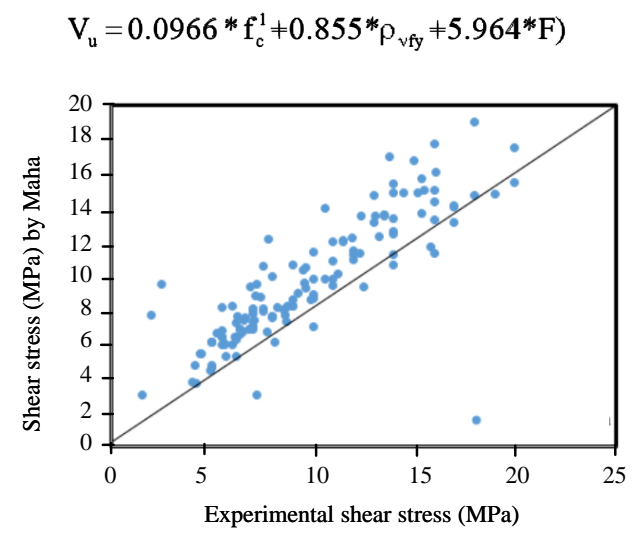

Fig. 23: Comparison between experimental result and Ridha et al. (2012) equation

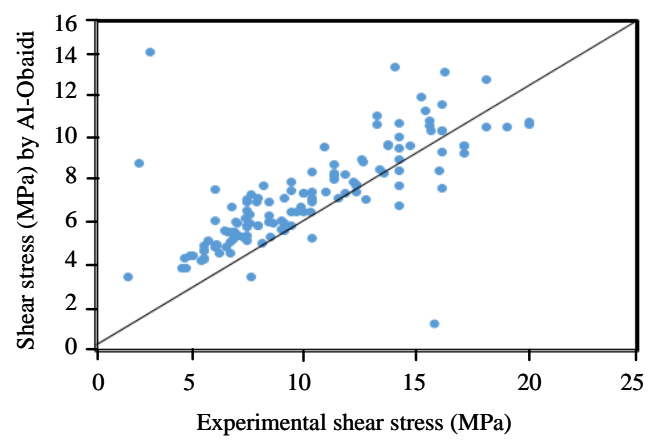

Fig. 24: Comparison between experimental result and Al-Obidid (1998) equation

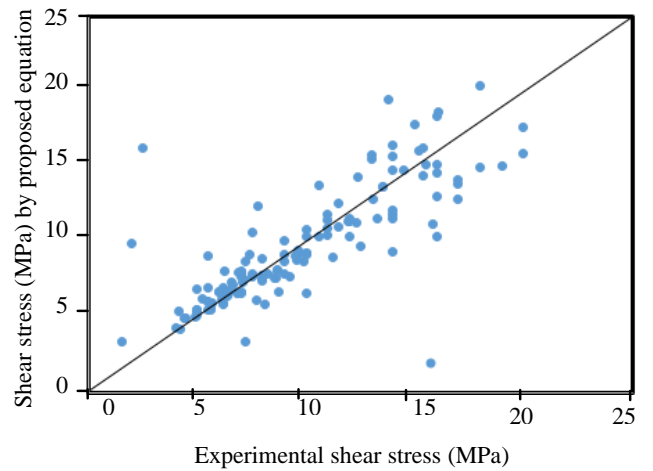

Fig. 25: Comparison between experimental results and proposed equation
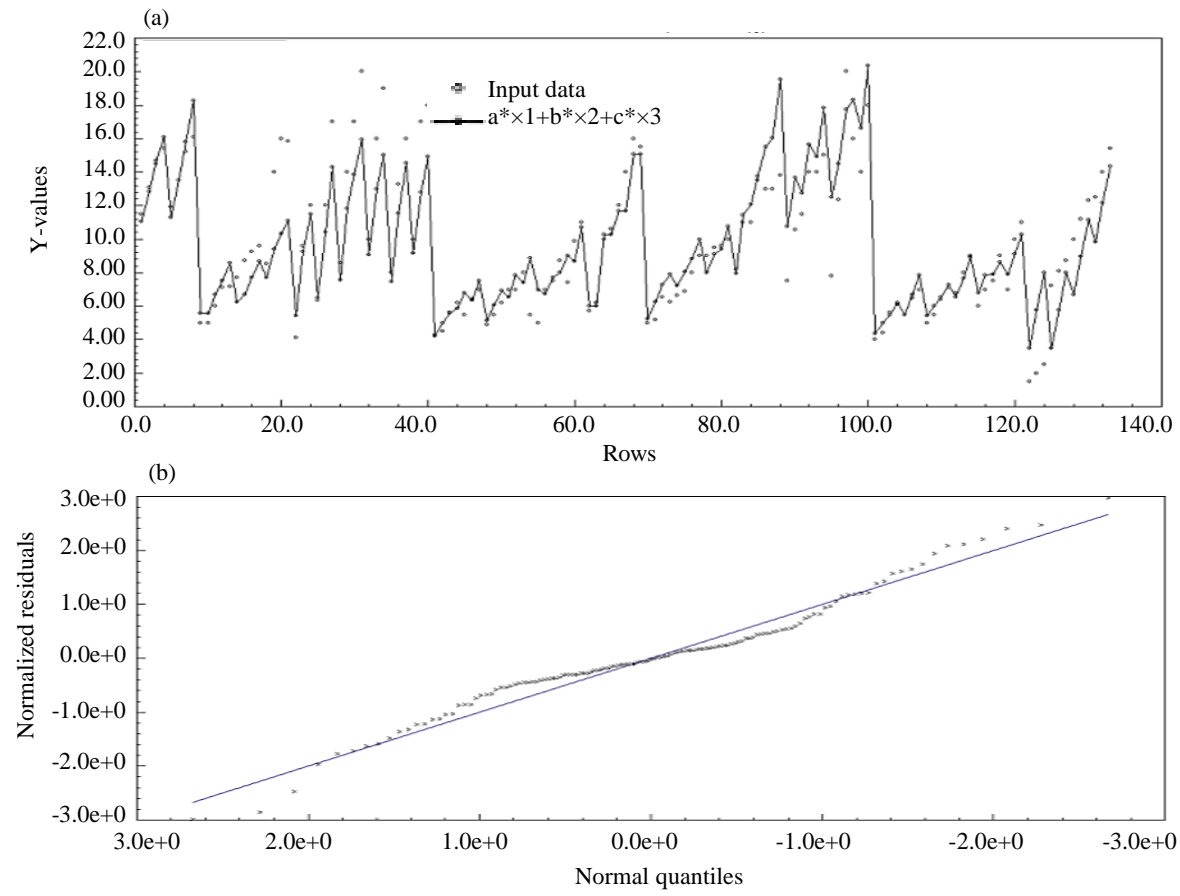

Fig. 26: Data fit regression analysis and residual normal probability: a) Model $\mathrm{a}^{*} \times 1+\mathrm{b}^{*} \times 2+\mathrm{c}^{*} \times 3$ (unlicensed copy) and b) Residual normal probability plot (unlicensed copy) 


\section{CONCLUSION}

Depending on the laboratory and finite element investigation results displayed, the subsequent conclusions are illustrated.

It is obvious from the experimental work that the addition of fibers by 1 and $2 \%$ volume fraction decreases the slump flow by 10 and $22 \%$, increasing $\mathrm{T}_{50}$ by 49 and $114 \%$ and reducing L-box by 9 and $17.5 \%$, respectively. This reduction of workability is due to presence of steel fibers that work as obstacle for the motion of mix components.

The hardening concrete tests concluded that the concrete properties in compressive, shear, bending and tensile strength relative to self-compacting concrete mixture casted without steel fibers.

The hardening concrete tests concluded that the concrete properties of compressive, shear, bending and tensile strength are decreased and this correlated with the exposed temperature degree.

Steel fiber self-compacted reinforced concrete has the ability to resists the raising in temperature larger than traditional concrete. Where concrete with (1\%) steel fiber self-compacted concrete has a preferred and excellent response that other concrete mixture with or without fiber after exposure to high heat degree.

From experimentation results it was obvious that the shear stress was developed and crack expanse reduced when the fibers were combined, this behavior is related to the pullout permanence and dowel response of fibers all that has led to significant remaining load carrying capacity in shear subjected failure and all molds have failed in the shear subjected zone.

Specimens with plain concrete show brittle failure with no warning before collapse but specimens with fibers developed first several separated small diagonal cracks that were later joined together and consequently the specimens failed in less brittle manner.

The self-compacted concrete crack width is decreased when the amount of steel fibers grow, all this is related to that steel fibers has the ability to prevent the generation of cracking in concrete section.

The cracks generated in specimens with non-fibrous self-compacted concrete are quite obvious and separated while in fibrous self-compacted concrete these cracks appear but it different from nonfibrous concrete which looks much finer and limited in a number.

The specimens which including the higher amount of shear reinforcement ratio revealed that the shear strength ability is much higher than those of lower shear reinforcement ones, both before and following exposure to appropriate temperature.
The predicted formula from regression investigation is recommended to be employed to evaluate shear stress of many types of concrete and its displays great compatibility with the laboratory results.

The nonlinear finite element examination by the application (ANSYS) can be managed to determine the performance of shear transfer specimens and can be applied to many parametric comparisons which display good compromise with laboratory results. Moreover, ANSYS reveals that the shear stress of the push-off specimens is highest at the top surface of the shear plane and reduced towards the middle.

\section{REFERENCES}

ACI., 2008. Self-consolidating concrete Los Angeles. American Concrete Institute, Michigan, USA.

Ahmed, S.M., 2013. The effect of elevated temperature on the properties on of self-compacting concrete reinforced by steel fiber. MSc Thesis, College of Engineering, University of Babylon, Hillah, Iraq.

Al-Feel, J.R., 2006. Experimental and numerical investigation of shear transfer with direct stress in steel fiber reinforced concrete. Ph.D Thesis, Civil Engineering Department, University of Mosul, Mosul, Iraq.

Al-Obidid, L., 1998. Direct shear of high strength concrete with fibers. MSc Thesis, University of Technology, Baghdad, Iraq.

Almusawee, G.M.H.H., 2012. Effect of using fibers on some mechanical properties of self compacting concrete. Iraqi J. Mech. Mater. Eng., 12: 616-629.

Boulekbache, B., M. Hamrat, M. Chemrouk and S. Amziane, 2012. Influence of yield stress and compressive strength on direct shear behaviour of steel fibre-reinforced concrete. Constr. Build. Mater., 27: 6-14.

Cuenca, E. and P. Serna, 2010. Shear Behavior of Self-Compacting Concrete and Fiber-Reinforced Concrete Push-Off Specimens. In: Design, Production and Placement of Self-Consolidating Concrete, Khayat, K., D. Feys (Eds.). Springer, Berlin, Germany, ISBN:978-90-481-9663-0, pp: 429-438.

Ferrara, L., Y.D. Park and S.P. Shah, 2007. A method for mix-design of fiber-reinforced self-compacting concrete. Cem. Concr. Res., 37: 957-971.

Gencel, O., W. Brostow, T. Datashvili and M. Thedford, 2011. Workability and mechanical performance of steel fiber-reinforced self-compacting concrete with fly ash. Compos. Interfaces, 18: 169-184. 
Khaloo, A.R. and N. Kim, 1997. Influence of concrete and fiber characteristics on behavior of steel fiber reinforced concrete under direct shear. ACI. Mater. J., 94: 592-601.

Kumar, H.N.R., Pavankumar, K.P. Nagaraja and R. Prabhakara, 2015. Influence of fibers on crack arrest mechanism and shear-friction behavior of different concrete using push-off specimen. Intl. Res. J. Eng. Technol., 2: 1139-1145.

Lee, G.G. and S.J. Foster, 2006. Behaviour of Steel Fiber Reinforced Mortar in Shear I: Direct Shear Testing. University of New South Wales, Australia, ISBN:9780858414112, Pages: 185.
Miao, B., J.C. Chern and C.A. Yang, 2003. Influences of fiber content on properties of self-compacting steel fiber reinforced concrete. J. Chin. Inst. Eng., 26: 523-530.

Mohuder, S.H. and M.A. Meshri, 2001. Study of shear transfer in reinforced concrete members by finite element method. Sci. J. Tikrit Univ. Eng. Sci., 891: 12-37.

Ridha, M.M., N.T. Hamad and K.F. Sarsam, 2012. Predicting the strength of fiber reinforced high performance concrete based on push-off tests. Eng. Technol. J., 30: 1187-1202. 